\title{
Correction to: The Peroneal Tendons
}

\author{
Mark Sobel
}

Correction to: M. Sobel (ed.), The Peroneal Tendons, https://doi. org/10.1007/978-3-030-46646-6

This title was recently Published. The title of Chapter 23, was incorrectly published as "Peroneal Tendon Pathology Associated with Calcaneous Fractures".

The correct title should read "Peroneal Tendon Pathology Associated with Calcaneus Fractures".

Also the affiliation of the author Dr. Michael Gans was published incorrectly in Chapters 7 and 24.

The correct affiliation should read, "PTSMC Orthopedic Residency Program, West Hartford, CT Physical Therapy and Sports Medicine Centers, Guilford, CT".

\footnotetext{
The updated versions of the chapters can be found at https://doi.org/10.1007/978-3-030-46646-6_7 https://doi.org/10.1007/978-3-030-46646-6_23 https://doi.org/10.1007/978-3-030-46646-6_24
} 